\title{
Pharmacogenetic of Clopidogrel and Platelet Function Testing: The Clinical Impact
}

\author{
Ahmad Almeman $^{1^{\star}}$ and Hassan Khalaf ${ }^{2}$ \\ ${ }^{1}$ School of Medicine, Qassim University,Almulaida, Buraidah, Al Qassim, Saudi Arabia \\ ${ }^{2}$ Cardiology Interventional Group, Prince Sultan Cardiac Center (PSCC), Buraidah, Al Qassim, Saudi Arabia \\ *Corresponding author: Ahmad Almeman, School of Medicine, Qassim University,Almulaida, Buraidah, Al Qassim, Saudi Arabia, Tel: 0548889712; E-mail: \\ meman@qu.edu.sa
}

Received date: Dec 15, 2015, Accepted date: Jan 13, 2016, Publication date: Jan 18, 2016

Copyright: (c) 2016 Almeman A, et al. This is an open-access article distributed under the terms of the Creative Commons Attribution License, which permits unrestricted use, distribution, and reproduction in any medium, provided the original author and source are credited.

Cytochrome 450 (CYP 450) 2C19 is a well known polymorphic metabolising enzyme which is responsible for converting clopidogrel to its active form [1]. Measuring the resulting activity based on Platelet Reactivity Units (PRU) or inhibition rates of the platelet is well correlated with the genetic polymorphism in several studies worldwide [1-3]. However, the debate is whether the polymorphism or PRU may result in any significant clinical endpoint.

Generally there are two main confounders, the expected time of the clinical endpoints, and the time of measuring the PRU/inhibition rate following clopidogrel initiation. For the first issue, most of the studies measured the clinical endpoints within 1-24 months, and hence long term endpoints can't be conclusive [4-6]. For the other issue, clopidogrel PRU is difficult to be assumed stable especially for the first month following initiation [7]. Thus, if the study measured it after 5 days and considered long term clinical endpoints, it is unlikely to spot a real effect, if exist [8-12]. Accordingly, it is difficult to predict the clinical response for individual patients in in short-term studies and just after clopidogrel initiation.

We presented two different studies: in-patient and out-patient cohorts, both showed clear polymorphic population, but no clinical associations were seen in both $[7,13,14]$. The PRUs were significantly different in our out-patient cohort compared to the in-patient cohort. This is likely due to the unstable patterns of clopidogrel metabolism during initiation and hence variable PRUs in the first month. After the PRUs reached the steady-state, a clear significant difference based on pharmacogenetic can be detected. The adequacy of PRUs may be assessed early during in-patient course but likely to differ significantly during the first days after initiation. Thus, if clopidogrel is on board, it may be judicious to assess the PRU just before the cardiac procedure and perhaps after one month of initiation to ensure a reasonable PRU for in-hospital stay and out-patient follow up.

No concrete PRU levels were well established. Besides, PRU have been proposed to range from 60-240 in several studies with heterogeneous cohorts. These studies contain multiple confounders, including: gender, age, diseases, medications, and procedures. For instance, while smokers showed more sensitivity toward PRU, females might show higher PRUs than males [15]. Therefore, It is suggested that a PRU cut-off value be assessed for each hospital based on their clinical data, as there is no clear consensus on the optimal PRUs.

Although the clinical benefits are very controversial, the possible clinical endpoints are devastating. It is clinically questionable to leave patients on clopidogrel with very minimal inhibitions when effective alternatives are available. All the proposed clinical decisions have been included in some of the guidelines under investigations or at most with very week level of evidence, including Up-to-Date $[16,17]$. At the same time, some guidelines have given the preference to Prasugrel or Ticagrelol in favour of clopidogrel in many clinical scenarios. Once a clinical endpoint occurred while on clopidogrel, most of the guidelines advocate screening for clopidogrel resistance and changing to other alternatives.

Finally, we suggest for clinicians to bear in mind clopidogrel resistance and to run PRU if feasible and easily accessible. If the patient shows very low PRU/inhibition rates lower than all the published data, it may be judicious to change to other alternatives. If alternatives are not available, close monitoring with patient education are warranted.

\section{References}

1. Sofi F, Giusti B, Marcucci R, Gori AM, Abbate R, et al. (2011) Cytochrome $\mathrm{P} 4502 \mathrm{C} 19^{\star} 2$ polymorphism and cardiovascular recurrences in patients taking clopidogrel: a meta-analysis. Pharmacogenomics J 11: 199-206.

2. Langaee TY, Zhu HJ, Wang X, El Rouby N, Markowitz JS, et al. (2014) The influence of the CYP2C19*10 allele on clopidogrel activation and CYP2C19² genotyping. Pharmacogenet Genomics 24: 381-386.

3. Delgado Almandoz JE, Kadkhodayan Y, Crandall BM, Scholz JM, Fease JL, et al. (2014) Variability in initial response to standard clopidogrel therapy, delayed conversion to clopidogrel hyper-response, and associated thromboembolic and hemorrhagic complications in patients undergoing endovascular treatment of unruptured cerebral aneurysms. J Neurointerv Surg 6: 767-773.

4. Altheeb Z, Sbitan A, Shabiah M, Debari V, Hamdan A, et al. (2015) Platelet Reactivity Unit in Predicting Risk of Bleeding in Patients Undergoing Coronary Artery Bypass Graft Surgery. Am J Ther.

5. Reed GW, Kumar A, Guo J, Aranki S, Shekar P, et al. (2015) Point-of-care platelet function testing predicts bleeding in patients exposed to clopidogrel undergoing coronary artery bypass grafting: Verify pre-op TIMI 45--a pilot study. Clin Cardiol 38: 92-98.

6. Aradi D, Kirtane A, Bonello L, Gurbel PA, Tantry US, et al. (2015) Bleeding and stent thrombosis on P2Y12-inhibitors: collaborative analysis on the role of platelet reactivity for risk stratification after percutaneous coronary intervention. Eur Heart J 36: 1762-1771.

7. Rasool S, Khalaf H, Almeman A, AlOrainy MM (2015) Assessment of steady-state clopidogrel reactivity by using platelet reactivity units. Am J Ther 22: 182-185.

8. Brar SS, ten Berg J, Marcucci R, Price MJ, Valgimigli M, et al. (2011) Impact of platelet reactivity on clinical outcomes after percutaneous coronary intervention. A collaborative meta-analysis of individual participant data. J Am Coll Cardiol 58: 1945-1954.

9. Siasos G, Oikonomou E, Zaromitidou M, Kioufis S, Vavuranakis M, et al. (2014) High platelet reactivity is associated with vascular function in patients after percutaneous coronary intervention receiving clopidogrel. Int J Cardiol 177: 192-196. 
Citation: Almeman A, Khalaf H (2016) Pharmacogenetic of Clopidogrel and Platelet Function Testing: The Clinical Impact. J Blood Disord Transfus 7: 334. doi:10.4172/2155-9864.1000334

Page 2 of 2

10. Li S, Shi Y, Wang H, Zhang W, Liu J (2015) Impact of cytochrome P450 $2 \mathrm{C} 19^{\star} 2$ polymorphism on intra-stent thrombus assessed by follow-up optical coherence tomography in Chinese patients receiving clopidogrel. J Thromb Thrombolysis 40: 88-96.

11. Sawada T, Shinke T, Shite J, Honjo T, Haraguchi Y, et al. (2011) Impact of cytochrome $\mathrm{P} 4502 \mathrm{C} 19^{\star} 2$ polymorphism on intra-stent thrombus after drug-eluting stent implantation in Japanese patients receiving clopidogrel. Circ J 75: 99-105.

12. Nakamura M, Isshiki T, Kimura T, Ogawa H, Yokoi H, et al. (2015) Optimal cutoff value of $\mathrm{P} 2 \mathrm{Y} 12$ reaction units to prevent major adverse cardiovascular events in the acute periprocedural period: post-hoc analysis of the randomized PRASFIT-ACS study. Int J Cardiol 182: 541-548.

13. Khalaf $\mathrm{H}, \mathrm{Al}$ Meman AA, Rasool S (2015) Impact of Cytochrome P450 $2 \mathrm{C} 19^{\star} 2$ and ${ }^{*} 3$ on Clopidogrel Loading Dose in Saudi Patients with Acute Coronary Syndrome. Drug Metab Lett .
14. Campo G, Parrinello G, Ferraresi P, Lunghi B, Tebaldi M, et al. (2011) Prospective evaluation of on-clopidogrel platelet reactivity over time in patients treated with percutaneous coronary intervention relationship with gene polymorphisms and clinical outcome. J Am Coll Cardiol 57: 2474-2483.

15. Gagne JJ, Bykov K, Choudhry NK, Toomey TJ, Connolly JG, et al. (2013) Effect of smoking on comparative efficacy of antiplatelet agents: systematic review, meta-analysis, and indirect comparison. BMJ 347: f5307.

16. Bauer T, Bouman HJ, van Werkum JW, Ford NF, ten Berg JM, et al. (2011) Impact of CYP2C19 variant genotypes on clinical efficacy of antiplatelet treatment with clopidogrel: systematic review and meta-analysis. BMJ 343: d4588.

17. Nissen SE (2011) Pharmacogenomics and clopidogrel: irrational exuberance? JAMA 306: 2727-2728. 